\title{
Efeito da temperatura e período de molhamento sobre o desenvolvimento de lesões de Colletotrichum musae em banana
}

\author{
Wagner Rogério Leocádio Soares Pessoa ${ }^{1 *}$, Sônia Maria Alves de Oliveira ${ }^{1}$, Suzana Alencar Freire Dantas ${ }^{2}$, Selma \\ Cavalcanti Cruz de Holanda Tavares ${ }^{3}$, Alice Maria Gonçalves Santos ${ }^{*}$
}

${ }^{1}$ Laboratório de Patologia Pós-Colheita, UFRPE/DEPA/Fitossanidade, 52171-900 Recife-PE, ${ }^{2}$ IPA, 50761-000 Recife-PE, ${ }^{3}$ Embrapa Solos/UFP, 51020-240 Recife-PE, *Bolsista CNPq

Autor para correspondência: Rogério Leocádio Soares Pessoa

Data de chegada: 07/10/2004. Aceito para publicação em: 20/11/2006.

\section{RESUMO}

Pessoa, W.R.L.S; Oliveira, S.M.A.; Dantas, S.A.F.; Tavares, S.C.C. de H.; Santos, A.M.G. Efeito da temperatura e período de molhamento sobre o desenvolvimento de lesões de Colletotrichum musae em banana. Summa Phytopathologica, v.33, n.2, p.147-151, 2007.

A banana é a segunda fruta mais consumida no mundo, porém do campo até o mercado consumidor algo em torno de $40 \%$ é perdido devido entre outras causas as doenças pós-colheita e a mais significativa é a antracnose. Diante da necessidade do conhecimento de fatores ambientais que condicionam estas perdas, o trabalho objetivou avaliar métodos de inoculação (com discos de BDA e estruturas do patógeno e suspensão de conídios com e sem ferimento) e a influência da temperatura $\left(10,15,20,25\right.$ e $\left.30^{\circ} \mathrm{C}\right)$ e do período de molhamento $(0,12,24$ e $36 \mathrm{~h})$ sobre o desenvolvimento de Colletotrichum musae em banana. As frutas foram inoculadas com 17 isolados de C. musae onde todos mostraram-se patogênicos quando inoculados com ferimento independentemente do tipo de inóculo utilizado. No experimento envolvendo temperatura e período de molhamento, utilizou-se três isolados de C. musae, MAG2, SFV1 e FSA, que se comportaram como mais agressivo, intermediário e pouco agressivo, respectivamente. As temperaturas em torno de $20,25 \mathrm{e}$ $30{ }^{\circ} \mathrm{C}$ e os períodos de molhamento testados favoreceram um maior desenvolvimento de lesões, sendo as maiores lesões observadas em temperaturas ao redor de 25 e $30^{\circ} \mathrm{C}$, com redução à medida que ocorria uma diminuição da temperatura para todos os isolados testados. A temperatura em torno de $15{ }^{\circ} \mathrm{C}$ proporcionou o menor desenvolvimento da doença.

Palavras-chave adicionais: antracnose, pós-colheita, patogenicidade, fatores ambientais.

\section{ABSTRACT}

Pessoa, W.R.L.S; Oliveira, S.M.A.; Dantas, S.A.F.; Tavares, S.C.C. De H.; Santos, A.M.G. Effect of temperature and wet period on the development of Colletotrichum musae lesions in banana. Summa Phytopathologica, v.33, n.2, p.147-151, 2007.

The banana is the second more consumed fruit in the world, but there is a product loss of about $40 \%$ from field to consuming market due to several factors including the postharvest diseases, being the anthracnose most significative among them. Considering the necessity of studying the environmental factors that affect this losses, the objective of this work was to evaluate methods of inoculation (PDA discs with pathogen structures and suspension of conidia with and without wound) and the influence of temperature $(10,15,20,25$ and $\left.30^{\circ} \mathrm{C}\right)$ and wet period $(0,12,24$ and 36 hours $)$ on the development of Colletotrichum musae on banana. The fruits were inoculated with 17 isolated of C. musae and all of them showed pathogenicty when inoculated with wound independently of the type of inoculum used. In the trial envolving temperature and wet period three isolates of $C$. musae: MAG2, SFV1 and FSA were used, which showed high, intermediate and low aggressiveness, respectively. The temperatures around 20,25 and $30^{\circ} \mathrm{C}$ and all wet periods tested favored the lesion development, being observed the biggest lesions under temperatures of about 25 and $30^{\circ} \mathrm{C}$, as well as lesion reduction induced by all isolates with decreasing of temperature. The temperature around $15^{\circ} \mathrm{C}$ favored the lowest disease development on banana fruit.

Additional keywords: anthracnose, postharvest, pathogenicity, environmental factors.

A produção mundial de banana em 2006, foi de aproximadamente 72,6 milhões de toneladas, tendo a Ásia como seu maior produtor, contribuindo com cerca de $40 \%$ da produção mundial (10). O Brasil possui destaque no cenário mundial, com uma produção de 6.802 milhões de toneladas e uma área plantada de 516 mil hectares (12), o que coloca o país em segundo lugar em produção e área colhida (10). Embora seja o segundo maior produtor, a participação brasileira no mercado internacional é insignificante, em razão de diversos fatores, entre eles sua precária estrutura comercial, baixa qualidade de produção e, principalmente, os substanciais danos pós-colheita, podendo estas ocorrer devido a inúmeros fatores como o físico, o fisiológico e o microbiológico (18).

Dentro do fator microbiológico, inúmeros organismos (fungos, bactérias, nematóides e vírus) prejudicam o desenvolvimento da bananeira merecendo destaque na pós-colheita o fungo Colletotrichum musae (Berk. \& Curtis) von Arx., agente causal da antracnose, o qual prejudica a comercialização e o consumo 'in natura', podendo ocasionar danos de até $40 \%$ da produção $(6,19)$.

O conhecimento de condições favoráveis aos fitopatógenos na interação patógeno-hospedeiro é imprescindível. Assim, o estádio 
fenológico em que o hospedeiro se torna mais suscetível, a faixa de temperatura e porcentagem de umidade relativa do ar, para o estabelecimento da doença devem ser definidos para cada patossistema (3).

Diversos autores têm verificado o efeito da temperatura e período de molhamento sobre o desenvolvimento de doenças fúngicas $(8,13$, 14, 20, 21). O primeiro afeta o crescimento dos fungos, sendo que muitos fungos pós-colheita, geralmente, crescem entre 20 a $25^{\circ} \mathrm{C}(1)$. $\mathrm{O}$ segundo é outro fator do ambiente considerado indispensável para a germinação da maioria dos esporos e para penetração do tubo germinativo, além de aumentar a suscetibilidade a certos patógenos afetando a incidência e a severidade da doença (2).

Porém, pouco destes estudos são encontrados envolvendo espécies de Colletotrichum (22) e reduzido número de estudos em pós-colheita de frutas (21). Diante das consideráveis perdas pós-colheita causadas por C. musae em banana e da necessidade do estudo de fatores ambientais que condicionam estas perdas, o trabalho teve por objetivo avaliar o efeito da temperatura e períodos de molhamento sobre o desenvolvimento da antracnose da banana.

\section{MATERIAL E MÉTODOS}

\section{Obtenção dos isolados}

Os isolados de C. musae foram obtidos de bananas apresentando sintomas de antracnose nas seguintes cultivares: Subgrupo Prata (Prata e Pacovan), Subgrupo Terra (D'Angola) e Maçã, todas pertencentes ao grupo genômico AAB (19), proveniente das principais regiões produtoras de Pernambuco (SVF1, SVF2, SVF3, SVF4 - São Vicente Ferri, CSA - Cabo de Santo Agostinho, PAU - Paulista, JBO - Jaboatão dos Guararapes, GRT - Gravatá, REC - Recife, AMJ1, AMJ2 Amaraji, MCD1, MCD2 - Machado, VIC - Vicência), Alagoas (MAG1, MAG2 - Maragogi), e Bahia (FSA - Feira de Santana). As frutas inicialmente foram lavadas com água e sabão e colocadas para secar sobre papel-toalha. Em seguida, acondicionou-se em câmara úmida composta de saco plástico previamente umedecido com água destilada esterilizada (ADE), por 48 horas à $29 \pm 2{ }^{\circ} \mathrm{C}$ e umidade relativa de $64 \%$ após retirada da câmara úmida. Após o período de incubação, a massa de esporos foi cuidadosamente retirada da superfície da fruta com auxílio de um estilete esterilizado, plaqueando-se em meio de cultura BDA (Batata-Dextrose-Ágar), incubando-se em condições de laboratório até o crescimento do fungo e transferindo-os, em seguida, para tubos de ensaio contendo meio BDA, para realização de ensaios posteriores.

\section{Teste de patogenicidade e métodos de inoculação}

$\mathrm{O}$ teste de patogenicidade foi realizado em bananas cv. Pacovan, provenientes da Companhia de Abastecimento e Armazéns Gerais do estado de Pernambuco (CEAGEPE), no estádio de maturação comercial entre 2 e 4 (5). As frutas foram lavadas individualmente com água e sabão e colocados para secar à temperatura ambiente. As inoculações procederam-se de duas formas: na primeira, utilizou-se um disco de meio BDA contendo estruturas de C. musae colocado na superfície da fruta, com ou sem ferimento, ferimento este obtido através de um furador com oito furos de $2 \mathrm{~mm}$ de profundidade. Na segunda, obteve-se uma suspensão de conídio na concentração de 4 x $10^{6}$ conídios. $\mathrm{mL}^{-1}$ inoculada na superfície da banana com ou sem ferimento, usando-se para isso um pipetador automático de $10 \mathrm{~mL}$. As inoculações foram realizadas na extremidade da banana. A fruta testemunha foi inoculada com disco contendo apenas meio BDA e $10 \mathrm{~mL}$ de ADE, com ou sem ferimento. Em seguida, acondicionou-se individualmente as frutas em câmara úmida por 48 horas à $29 \pm 2{ }^{\circ} \mathrm{C}$ e umidade relativa de $64 \%$, mensurada após retirada da câmara úmida. $\mathrm{O}$ período de incubação foi de sete dias.

A avaliação foi realizada mediante o desenho sobre papel-manteiga, da área lesionada na superfície da fruta por meio do programa IMAGE TOOL.

O ensaio foi inteiramente casualizado em arranjo fatorial $(2 \times 2 \times 17)$ utilizando-se quatro repetições, sendo dois tipos de inóculo (disco de meio e suspensão de conídios), dois métodos de inoculação (com e sem ferimento) e 17 isolados de C. musae. Foi analisado o tamanho das lesões em $\mathrm{cm}^{2}$ e as médias comparadas pelo teste de Tukey ao nível de $5 \%$ de probabilidade, utilizando-se o programa SANEST.

Efeito da temperatura e período de molhamento sobre o desenvolvimento de Colletotrichum musae em banana

O experimento foi conduzido no Laboratório de Patologia PósColheita da Universidade Federal Rural de Pernambuco, em bananas cv. Pacovan obtidas da CEAGEPE, no estádio de maturação comercial entre 2 e 3, desinfestados com água corrente e sabão e postos para secar em papel toalha. Os isolados de C. musae utilizados foram MAG2, SVF1 e FSA, selecionados com base no teste de patogenicidade, onde o primeiro foi mais agressivo, o segundo intermediário e o terceiro pouco agressivo. As bananas foram feridas com furador de oito furos com $2 \mathrm{~mm}$ de profundidade e, posteriormente, colocados $10 \mathrm{~mL}$ da suspensão de conídios na concentração de $4 \times 10^{6}$ conídios. $\mathrm{mL}^{-1}$ nas extremidades das mesmas, mantidas por cinco dias em câmara incubadora (BOD), sob temperatura (T) de $10,15,20,25$ e $30 \pm 1{ }^{\circ} \mathrm{C}$ e períodos de molhamento (PM) de 0, 12, 24 e 36 horas com umidade relativa do ar $86,5 \%$. Frutas testemunhas foram inoculadas com ADE e submetidas aos mesmos tratamentos. Após o período de incubação, avaliou-se o desenvolvimento dos sintomas através da área da lesão em $\mathrm{cm}^{2}$, obtida através do programa IMAGE TOOL.

O delineamento estatístico utilizado foi inteiramente casualizado em arranjo fatorial $5 \times 4$ ( $\mathrm{T} \times \mathrm{PM})$ com cinco repetições por tratamento. A média dos dados obtida foi submetida à análise de regressão múltipla, com o auxílio do programa STATISTICA for Windows Release 5.1 (StartSoft Inc., Tulsa-OK, 2000).

\section{RESULTADOS E DISCUSSÃO}

\section{Teste de patogenicidade e métodos de inoculação}

Todos os isolados de C. musae mostram-se patogênicos quando inoculados em banana com ferimento (Tabela 1), sendo observado no local da inoculação uma leve depressão e a presença da massa de esporos de coloração rosa sobre os mesmos. Os isolados REC e JBO comportaram-se como não patogênicos quando inoculados sem ferimento, utilizando-se disco e suspensão de conídios. Já os isolados SVF3, SVF4, MAG2 e MCD2, comportaram-se semelhantes aos anteriores, porém quando inoculados com suspensão sem ferimento. A penetração ocorre após a formação de apressórios, que são essenciais para os processos de infecções quiescente e subcuticular durante os primeiros estádios de desenvolvimento da fruta. $\mathrm{O}$ apressório em contato com a superfície do hospedeiro adere a cutícula e emite hifas de penetração, sendo a invasão muito rápida em tecido com ferimento, em comparação com a penetração direta através da superfície intacta do hospedeiro, conduzindo a produção de sintomas típicos de antracnose (11).

O método de inoculação com ferimento permitiu as maiores lesões sobre banana, não ocorrendo diferença significativa entre os isolados do patógeno quando inoculados sem ferimento. Este fato pode estar 
Tabela 1. Tamanho de lesões em $\mathrm{cm}^{2}$ sobre frutas de banana ocasionados por Colletotrichum musae, após sete dias de inoculação

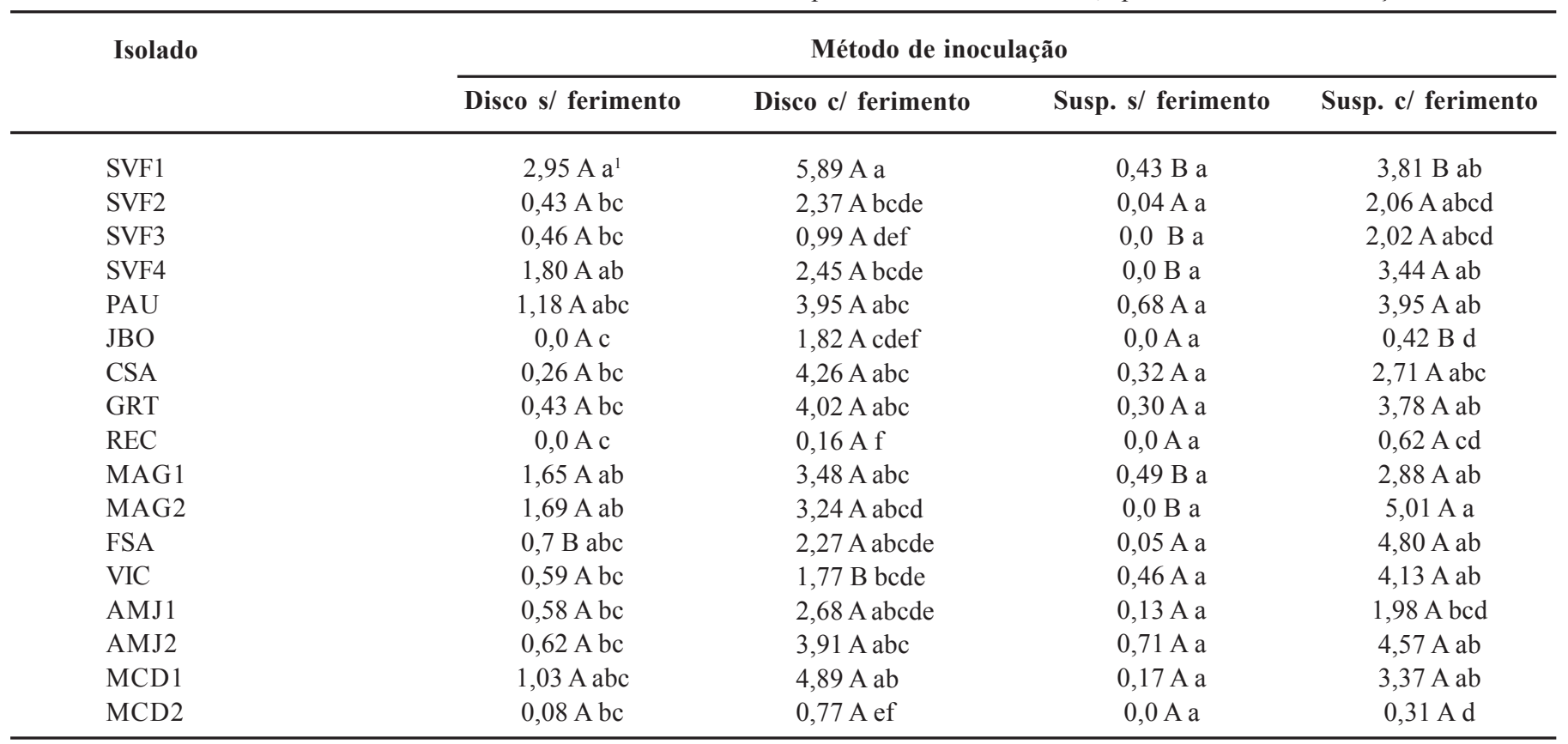

$\mathrm{CV}(\%)=\quad 22,44$

${ }^{1}$ Média de quatro repetições. Letras maiúsculas diferem entre si na mesma linha e letra minuscúlas diferem entre si na mesma coluna pelo teste de Tukey $(\mathrm{P}=0,05)$.

relacionado com a cerosidade natural e o formato da fruta que provavelmente dificultou o processo infeccioso de $C$. musae quando inoculado com a suspensão de conídios nas frutas pelo método sem ferimento. O método de inoculação utilizando-se suspensão de conídios justifica-se pela padronização da quantidade de inóculo depositada sobre a superfície do hospedeiro, além da inoculação com o disco de meio de cultura contendo estruturas do patógeno possuir uma fonte extra de substrato, coisa que não ocorre na natureza. Geralmente, frutos verdes são mais resistentes a patógenos, devido à presença de fitoalexinas e outros compostos. Em banana, a infecção tem início no campo, onde os esporos são depositados sobre as frutas, penetrando no tecido ficando em infecções quiescentes (17). Segundo Chillet et al. (4) trabalhando no patossistema banana x C. musae, demonstrou que a idade fenológica é um fator chave na suscetibilidade ao patógeno. Ainda de acordo com os autores, frutas em avançado estádio de maturação são altamente suscetibilidade a infecções por C. musae, enquanto que frutas verdes ou em baixo estádio de maturação apresentam maior resistência a infecção.

Efeito da temperatura e período de molhamento no desenvolvimento de Colletotrichum musae em banana

A caracterização da doença se dá pela formação de lesões escuras e deprimidas. Estas, sob condições de alta umidade, cobrem-se de frutificação rosada a salmão, a polpa não é atingida, exceto quando exposta à alta temperatura e umidade, ou quando o fruto se encontra em avançado estádio de maturação $(6,7)$.

A superfície de resposta para estimar o tamanho da lesão (Figura 1) produzida pelos isolados de C. musae (MAG2, SFV1 e FSA) foi obtida através das funções:

LMAG2 $=2,968-0,412 \mathrm{~T}-0,105 \mathrm{PM}+0,018 \mathrm{~T}^{2}+0,002 \mathrm{~T} * \mathrm{PM}$ $+0,002 \mathrm{PM}^{2}$;

LSFV1 $=1,185-0,243 \mathrm{~T}+0,04 \mathrm{PM}+0,013 \mathrm{~T}^{2}-9,538-4 \mathrm{~T}^{*} \mathrm{PM}-$
$6,486-4 \mathrm{PM}^{2}$

LFSA $=2,045-0,296 \mathrm{~T}-0,009 \mathrm{PM}+0,013 \mathrm{~T}^{2}-8,955-4 \mathrm{~T} * \mathrm{PM}$ $+6,382-4 \mathrm{PM}^{2}$.

Onde $\mathrm{T}=$ temperatura e $\mathrm{PM}=$ período de molhamento.

Todas as temperaturas e períodos de molhamento testados proporcionaram desenvolvimento de lesões sobre a banana, verificando-se que as temperaturas em torno de 20 a $30{ }^{\circ} \mathrm{C}$ proporcionaram maiores lesões, sendo estas reduzidas à medida que a temperatura diminuía para os isolados testados (Figura 1). Resultados semelhantes foram obtidos por Dillard (9), no patossitema C. coccodes $\mathrm{x}$ tomate, Lima Filho (14) no desenvolvimento da antracnose em maracujá amarelo, e Zaemey et al. (22), verificando o efeito de condições ambientais sobre a antracnose da banana, onde observaram que temperaturas em torno de 25 a $35^{\circ} \mathrm{C}$ proporcionaram os maiores índices de lesões. As temperaturas em torno de 10 a $15^{\circ} \mathrm{C}$ provocaram uma redução acentuada no desenvolvimento da lesão. À temperatura de $10{ }^{\circ} \mathrm{C}$, favoreceu o "chilling" (distúrbio físiológico causado pelo frio) sobre as frutas, apresentando-se com estrias marromavermelhadas, algumas não atingiram a maturação e as que amadureceram ficaram sem brilho. Diversos autores $(15,16,21)$ também observaram que temperaturas abaixo de $13{ }^{\circ} \mathrm{C}$ provocam nas frutas da bananeira esse dano.

A temperatura em torno de $15{ }^{\circ} \mathrm{C}$ na ausência do período de molhamento proporcionou o melhor controle no desenvolvimento da antracnose em bananas. Resultado semelhante foi obtido por Zaemey et al. (22), quando estudou o efeito da temperatura e condições ambientais sobre o desenvolvimento da antracnose da banana.

De acordo com Chillet et al. (4), o aumento na temperatura e períodos chuvosos esta diretamente associado ao aumento na infecção por C. musae, e que a temperatura é uma fator preponderante a esse patossistema influenciando o aumento da infecção e acelerando o estádio de maturação e, conseqüentemente, as perdas provocadas pelo 


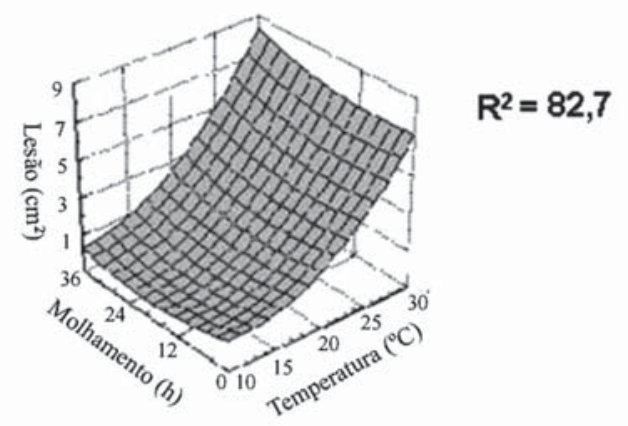

LSVF $1=1,185-0,243 \mathrm{~T}+0,04 \mathrm{PM}+0,013 \mathrm{~T}^{2}-9,538-4 \mathrm{~T} * \mathrm{PM}-6,486-4 \mathrm{PM}^{2}$

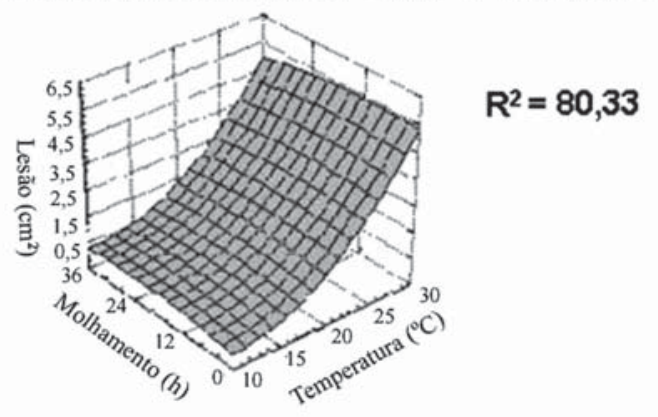

LFSA $=2,045-0,296 \mathrm{~T}-0,009 \mathrm{PM}+0,013 \mathrm{~T}^{2}-0,955-4 \mathrm{~T}^{*} \mathrm{PM}+6,302-4 \mathrm{M}^{2}$

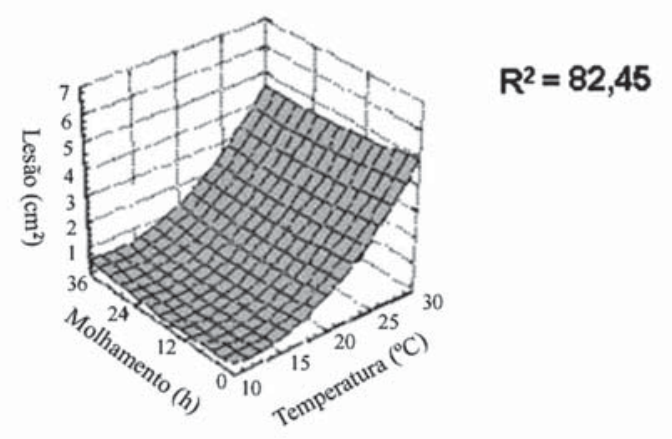

Figura 1. Efeito da temperatura e período de molhamento em bananas inoculadas com Colletotrichum musae, após cinco dias de incubação.

patógeno.

O aumento da duração do período de molhamento influenciou o desenvolvimento de lesões maiores em todas as temperaturas testadas, sendo que as frutas submetidas ao período de molhamento de 36 horas associado às temperaturas ao redor de 25 a $30{ }^{\circ} \mathrm{C}$ proporcionaram as maiores lesões sobre as mesmas. De modo semelhante, Lima Filho (14) verificou efeito significativo da temperatura ao redor de $30{ }^{\circ} \mathrm{C}$ e período de molhamento em torno de 12 a 36 horas no desenvolvimento de lesões de isolados de $C$. gloeosporioides (Penz.) Penz.\& Sacc. sobre a antracnose do maracujá amarelo.

De modo geral, as temperaturas de 20,25 e $30{ }^{\circ} \mathrm{C}$ além de promover o maior desenvolvimento da antracnose em banana, também foram responsáveis pelas maiores lesões sobre a superfície da fruta. Para conservação das frutas, a faixa de temperatura em torno de $15{ }^{\circ} \mathrm{C}$ mostrou ser mais adequada por desfavorecer o desenvolvimento de $C$. musae e conservar a integridade física desejável as frutas da bananeira.
1. Adaskaveg, J.A.; Förster, H.; Sommer, N.F. Principles of postharvest pathology and management of decays of edible horticultural crops. In.: Kader, A.A. (Ed.). Postharvest technology of crops. 3. ed. California: University of California Agriculture and Natural, 2002. p. 163-193.

2. Agrios, G.N. Plant pathology. 5. ed. San Diego: Academic Press, 2005. 922p.

3. Borges Neto, C.R.; Mello, S.C.M.; Ribeiro, Z.M.A.; Ávila, Z.R.; Malty, J.; Fontes, E.M.G. Influência da idade da plante, período de molhamento de umidificação e concentração do inóculo no desenvolvimento de sintomas provocados por Cercospora caricis em tiririca. Fitopatologia Brasileira, Brasília, v.25, n.2, p.138-142, 2000.

4. Chillet, M.; Hubert, O.; Rives, M.J.; Lapeyre de Bellatre, L. Effects of the physiological age of bananas on their susceptibility to wound anthracnose due to Colletotrichum musae, Plant Disease, St. Paul, v. 90, p. 1181-1185, 2006.

5. Chitarra, M.I.F.; Chitarra, A.B. Pos-colleita de frutas e hortaliças: fisiologia e manuseio, Lavras: ESAL-FAEPE, 1990. 320p.

6. Cordeiro, Z.L.M.; Matos, A.P.; Kimati, H. Doenças da bananeira. In: Kimati, H.; Amorim, L.; Bergamin Filho, A.; Camargo, L.E.A.; Rezende, J.A.M. (Ed.). Manual de fitopatologia: doenças das plantas cultivadas. 4 ed. São Paulo: Agronômica Ceres, 2005. cap. 15, v. 2 , p.99-117.

7. Cordeiro, Z.J.M.; Matos, A.P. Doenças fúngicas e bacterianas. In: Cordeiro, Z.J.M. (Org.) Banana fitossanidade. Brasília: EMBRAPA - SPI, 2000. p.36-65.

8. Cutrim, F. de A. Caracterização fisiológica de Penicillium sclerotigenum e influência da temperatura e período de molhamento sobre a podridão verde do inhame. 2004. 71 f. Dissertação (Mestrado em Fitossanidade/Fitopatologia) - Universidade Federal Rural de Pernambuco, Recife.

9. Dillard, H.R. Effect of temperature, wetness duration, and inoculum density on infection and lesion development of Colletotrichum coccodes on tomato fruit. Phytopathology, St. Paul, v.79, p.10631066, 1989.

10. FAO. FAOSTAT - FAO statistical data bases. Roma: World Agricultural Information Centre, 2006. Disponível em: <http:// apps.fao.org>. Acesso em: 10 out. 2006.

11. Goos, R.D.; Tschirsch, M. Effect of environmental factors on spore germitation, spore survival, and growth of Gloeosporium musarum. Mycologia, Lancaster, v.54, p.353-367, 1962.

12. IBGE. Sistema IBGE de recuperação automática. Rio de Janeiro; 2006. Disponível em: http://www.sidra.ibge.gov.br/bda. Acesso em 10 out. 2006.

13. Leite, R.M.V.B.C.; Amorim. L. Influência da temperatura e do período de molhamento no monociclo da mancha de Alternaria em girassol. Fitopatologia Brasileira, Brasília, v.27, n.2, p.193-2000, 2002.

14. Lima Filho, R.M. Caracterização isoenzimática, inoculações cruzadas de Colletotrichum e influência da temperatura no desenvolvimento da antracnose em maracujá. 2003. 54f. Dissertação (Mestrado em Fitossanidade/Fitopatologia) - Universidade Federal Rural de Pernambuco, Recife.

15. Medina, J.C. Banana: cultura, matéria-prima, processamento e aspectos econômicos. 3. ed. Campinas: ITAL, 1993. 585 p.

16. Olorunda, A.O.; Meheriuk, M.; Looney, N.E. Some factors associated with the occurrence of chilling injury in banana. Journal of the Science of Food and Agriculture, New Jersey, v.29, p.213-218, 1978.

17. Pessoa, W.R.L.S.; Oliveira, S.M.A. Doenças da banana. In: Oliveira, S.M.A.; Terao, D.; Dantas, S.A.F.; Tavares, S.C.C.H. Patologia póscolheita: frutas, olerícolas e ornamentais tropicais. $1^{\circ}$ ed. Brasília: Embrapa Informação Tecnológica, 2006. 539-554 p.

18. Rangel, A.; Penteado, L.A.C.; Tonet, R.M. Cultura da banana. $2^{\text {a }}$ ed. Campinas: CATI, 2002. 91p.

19. Silva, S.O. Cultivares de banana para exportação. In: Cordeiro, Z.J.M. (Org.). Banana produção: aspectos técnicos. Brasília: EMBRAPA - SPI, 2000. p.30-38. 
20. Silva, S.R.; Rios, G.P.; Silva, S.C. Influência da resistência e do período de molhamento na infecção e desenvolvimento de lesões de ferrugem no feijoeiro. Fitopatologia Brasileira, Brasília, v.26, n.4, p.726-731, 2001.

21. Wilson, L.L.; Madden, L.V.; Ellis, M.A. Influence of temperature and wetness duration on infection of immature and mature straw- berry fruit by Colletotrichum acutatum. Phytopathology, St Paul, v.80, p.111-116, 1990.

22. Zaemey, A.B.Al.; Magan, N.; Thompson, A.K. In vitro studies of the effect of environmental conditions on the antracnose pathogen of bananas, Colletotrichum musae. International Biodeterioration \& Biodegradation, Barking, v. 33, p.369-381, 1994 